dầy diện cắt âm tính lớn hơn. Trong nhóm này, tỷ lệ phải phẫu thuật cắt thêm cũng thấp hơn. Kết quả thẩm mỹ của nhóm kết hợp tạo hình tốt hơn nhóm cắt rộng u đơn thuần.

\section{KẾT LUẬN}

Trong nghiên cứu, độ tuổi bệnh nhân khá trẻ, trẻ nhất 21 , vị trí u $1 / 4$ trên ngoài thường gặp nhất, giai đoạn I -IIA là chủ yếu. Thể tích vú trung bình và nhỏ chiếm đa số $90,3 \%$. Thời gian sống thêm không bệnh 5 năm là $92,6 \%$, sống thêm toàn bộ 5 năm là $95,6 \%$. Kết quả thẩm mỹ mức đạt chiểm 80,2\%. Các biến chứng của xạ trị ảnh hưởng đến kết quả thẩm mỹ thường xảy ra muộn vậy cần có theo dõi dài sau điều trị để có những kết luận chính xác hơn

\section{TÀI LIÊU THAM KHẢO}

1. GLOBOCAN (2018). Incidence, Mortality and Prevalence by cancer site, <https://gco.iarc.fr/today/ data/factsheets/cancers/ 20-Breast-fact-

2. Harsolia A, Kestin L, Grills I, Wallace M, Jolly $\mathbf{S}$, Jones $\mathbf{C}_{\text {, }}$ et al. "Intensity-modulated radiotherapy 2 . results in significant decrease in clinical toxicities compared with conventional wedge-based breast radiotherapy"'". Int J Radiat Oncol Biol Phys. 2007;68(5):1375-80.

4. Losken, C. S. Dugal, T. M. Styblo et al. (2014). A meta-analysis comparing breast conservation therapy alone to the oncoplastic technique. Ann Plast Surg, 72(2), 145 - 152

5. Pham Hồng Khoa (2016). Ung dụng phương pháp sinh thiết hạch cửa trong điều trị ung thư biểu mô tuyến vú giai đoạn sớm, Luận án Tiến sỹ Y học, Trường Đại học Y Hià Nội.

6. J. P. Pignol, I. Olivotto, E. Rakovitch et al. (2008). A multicenter randomized trial of breast intensity-modulated radiation therapy to reduce acute radiation dermatitis. J Clin Oncol, 26(13), 2085-92.

7. Tạ Văn Tờ (2004). Nghiên cứu hình thái học, hóa mô miễn dịch và giá trị tiên lượng của chúng trong ung thư biểu mô tuyến vú, Luận án Tiến sỹ Y học, Trường Đại học Y Hà Nội.

8. U. Veronesi, A. Luini, M. Del Vecchio et al. (1993). Radiotherapy after breast-preserving surgery in women with localized cancer of the breast. N Engl J Med, 328(22), 1587-91.

9. Hoàng Thanh Quang (2011). Đánh giá kết quả điều trị bảo tồn ung thư vú nữ giai đoạn I-II từ năm 2003-2006 tại Bệnh viện K, Luận văn Thạc sỹ Y học, Trường Đại học Y Hà Nội.

\title{
ĐÁNH GIÁ KẾT QUẢ HÓA TRỊ BỔ TRỢ PHÁC ĐỒ 4AC-4D TRÊN BỆNH NHÂN UTV GIAI ĐOẠN II -IIIA BỆNH VIỆN UNG BƯỚU THANH HÓA
}

\section{TÓM TẮT}

Mưc tiêu: Đánh giá kết quả sống thêm và một số yễu tổ liên quan trên bệnh nhân ung thư vú giai đoạn II-IIIA điều trị phác đồ hóa chất bổ trợ $4 \mathrm{AC}-4 \mathrm{D}$ (A: doxorubicine, $\mathrm{C}$; cyclophosphamide và $\mathrm{D}$ : docetaxel) áp dụng tại Bệnh viện Ung bướu Thanh Hóa. Đối tượng và phương pháp nghiên cứu: Bao gồm 74 bệnh nhân được chẩn đoán ung thư vú giai đoạn IIIIIA đã phẫu thuật triêtt căn, điêu trị hóa chất bổ trợ tại bệnh viện ung bướu Thanh Hóa, từ tháng 2 năm 2014 đến tháng 4 năm 2021. Kết quả: Tuổi trung bình của nhóm nghiên cứu là 46,62 $\pm 7,05$ tuổi.Tất cả 74 bệnh nhân đều hoàn thành 8 chu kỳ hóa chất $4 A C-$ $4 \mathrm{D}$, không có bệnh nhân nào dừng điêu trị. Thời gian nghiên cứu trung bình là 69 tháng, tỷ lệ sông thêm không bệnh sau 5 năm là $53,6 \%$ với thời gian sống thêm khống bệnh trung bình là $63,95 \pm 2,34$ tháng, tỳ

\footnotetext{
${ }^{1}$ Trường Đại học Y Hà Nội

²Bênh viên $K$

Chịu trách nhiệm chính: Nguyễn Thị Trang

Email: drtrang1989@gmail.com

Ngày nhận bài: 3.8.2021

Ngày phản biện khoa học: 5.10 .2021

Ngày duyệt bài: 15.10 .2021
}

Nguyễn Thị Trang ${ }^{1}$, Phạm Hồng Khoa ${ }^{2}$

lệ sống thêm toàn bộ sau 5 năm là $89,2 \%$ với thời gian sống thêm toàn bộ trung bình là $78,70 \pm 1,60$ tháng. Các yếu tố ảnh hưởng đến điều trị bao gồm giai đoạn bệnh, tình trạng thụ thể nội tiết, tình trang HER2. Kết luận: Áp dụng phác đồ 4AC-4D trên bệnh nhân ung thư vú bổ trợgiai đoạn II-IIIA tại bệnh viện Ung bướu Thanh Hóa có hiệu quả cao. bổ trợ.

Tư khóa: ung thư vú giai đoạn II-IIIA, 4AC-4D,

\section{SUMMARY \\ TREATMENT OUTCOME IN PATIENTS WITH STAGE II-IIIA BREAST CANCER TREATED \\ WITH ADJUVANT CHEMOTHERAPY IN \\ THANH HOA ONCOLOGY HOSPITAL}

Objectives: To evaluate survival outcomes and some related factors in patients with stage II-IIIA breast cancer treated with 4AC-4D (A: doxorubicine, C: cyclophosphamide and D: docetaxel) adjuvant chemotherapy. Subjects and methods: Including 74 patients diagnosed with breast cancer stage II-IIIA who underwent radical surgery, adjuvant chemotherapy at Thanh Hoa Oncology Hospital, from February 2014 to April 2021. Results: The mean age of the study group was $46.62 \pm 7.05$ years. All 74 patients completed 8 cycles of 4AC-4D chemotherapy, 
none of which stopped treatment. The mean study time was 69 months, the 5 -year disease-free survival rate was $53.6 \%$ with the mean disease-free survival time was $63.95 \pm 2.34$ months, the overall survival rate after 5 years was $89.2 \%$ with a mean overall survival time of $78.70 \pm 1.60$ months. Factors affecting treatment include stage, hormonal receptor status and HER2 status. Conclusion: Applying the 4AC-4D regimen on patients with stage II-IIIA adjuvant breast cancer at Thanh Hoa Oncology Hospital has high efficiency.

Keywords: breast cancer stage II-IIIA, 4AC-4D, adjuvant.

\section{I. ĐẶT VẤN ĐỀ}

Ung thư vú(UTV) là một bệnh lý toàn thân, đặc biệt khi xuất hiên di cằn hạch nách, điêu trị không còn là tại chỗ, tại vùng mà đó là sự kết hợp điều trị đa mô thức giữa các phương pháp phấu thuật, xạ trị, hóa chất, nội tiết và sinhhọc. Việc áp dụng một hay nhiều phương pháp điều trị là tùy thuộc vào mỗi trường hợp cụ thểnhư giai đoạn bệnh, loại mô học, tình trạng thụ thể nội tiết, yếu tố phát triển biểu mô, tuổi, toàn trạng và một số yếu tố khác.

Hóa trị bổ trợ sau phẫu thuật đóng vai trò quan trọng trong điêu trị ung thư vú ở giai đoạn sớm, mục đích tiêu diệt các tế bào ung thư vi di căn, giảm tái phát và kéo dài thời gian sống thêm cho người bệnh. Nhóm Anthracyclin đã được chứng minh là một trong các thuốc có hiệu quả cao trong điều trị ung thư vú, với tỷ lệ đáp ứng $41 \%$ khi dùng đơn độc và $62-70 \%$ khi phối hợp với các thuốc khác ở bệnh nhân chưa điều trị hóa chất ${ }^{1-4}$. Vì vậy, hầu hết các phác đồ hóa chất trong điêu tri ung thư vú đều có Anthracyclin.

Hiện nay phác đồ 4AC-4D đã được sử dụng rất rộng rãi và trở thành quy trình chuẩn trong điều trị UTV bổ trợ trước và bổ trợ sau phẫu thuật đối với nhiều nước trên thế giới cũng như ở Việt Nam. Tại bệnh viện Ung bướu Thanh Hóa chưa có nghiên cứu nào về vai trò hóa trị bổ trợ trong ung thư vú. Chính vì vậy chúng tôi nghiên cứu đề tài: Đánh giá kêt quả hóa trị bổ trợ phác đồ $4 A C-4 D$ bệnh nhân ung thư vú giai đoạn II-IIIA.
II. ĐỐI TƯỢNG VÀ PHƯƠNG PHÁP NGHIÊN CỨU 2.1. Đối tượng nghiên cứu:

- Tiêu chuẩn lựa chọn:

+ Bệnh nhân nữ chẩn đoán là UTV giai đoạn

II-IIIA và $\leq 70$ tuổi.

+ Được phẫu thuật triệt căn.

+ Được hóa chất bổ trợ sau phẫu thuật phác đồ 4AC-4D, điều trị nội tiết, xạ trị.

+ Không mắc ung thư khác.

+Không có bệnh chống chỉ định với thuốc Anthracyclin: các bệnh lý tim mạch nặng như suy tim, viêm cơ tim, nhồi máu cơ tim, phân suất tông máu trên siêu âm tim $\geq 50 \%$.

+ Chức năng gan, thận và tủy xương trong giới hạn bình thường.

+ Có đầy đủ hồ sơ bệnh án lưu trữ.

- Tiêu chuẩn loại trừ: không đáp ứng đủ tiêu chí trên.

\subsection{Phương pháp nghiên cứu}

- Thiết kế nghiên cứu: Nghiên cứu mô tả hồi cứu.

- Thời gian và địa điểm nghiên cứu:

+ Thời gian nghiên cứu từ tháng 02/2014 đến tháng 04/2021.

+ Địa điểm nghiên cứu tại Bệnh viện Ung bướu tỉnh Thanh Hóa.

-Phương pháp thu thập số liệu:

+ Thu thập số liệu theo mẫu bệnh án

+ Tất cả các thông tin thu thập từ hồ sơ bệnh án

- Phân tích số liệu: nhập liệu, xử lý và phân tích trênmáy tính bằng phần mềm SPSS 20.0

\section{KẾT QUẢ NGHIÊN CỨU}

\section{1. Đặc điểm đối tượng nghiên cứu}

3.1.1. Tuổi và giai đoạn bệnh. Trong số 74 bệnh nhân nghiên cứutuổi trung bình là 46,62 \pm 7,05. Nhóm tuổi cao nhất 40-49 có tỷ lệ 44,6\%.

3.1.2. Giai đoạn bệnh. Giai đoạn IIA chiếm tỷ lệ cao nhất 40,5\%; giai đoạn IIB là $25,7 \%$; giai đoạn IIIA có tỷ lệ 33,8\%.

\subsubsection{Hóa mô miển dịch}

Bảng 1. Hóa mô miễn dịch

\begin{tabular}{|c|c|c|c|c|c|c|}
\hline \multirow{2}{*}{ Thụ thể bộc lộ trên u u } & \multicolumn{2}{|c|}{ Dương tính } & \multicolumn{2}{c|}{ Âm tính } & \multicolumn{2}{c|}{ Tổng } \\
\cline { 2 - 7 } & Số BN (n) & Tỉ lệ (\%) & Số BN(n) & Tỉ lệ(\%) & Số BN(n) & Tỉ lệ(\%) \\
\hline ER & 49 & 66,2 & 25 & 33,8 & 74 & 100 \\
\hline PR & 53 & 71,6 & 21 & 28,4 & 74 & 100 \\
\hline ER và hoặc PR & 65 & 87,8 & 9 & 12,2 & 74 & 100 \\
\hline Thụthể HER2(2+),(3+) & 24 & 32,4 & 50 & 67,6 & 74 & 100 \\
\hline
\end{tabular}

Nhận xét: Tỷ lệthụ thể nội tiết (TTNT) dương tính cao 87,8\%. Tỷ lệHER2 âm tính 67,6\%; tỷ lệ HER2 dương tính (cả HER2 dương tính 2+ và 3+) thấp chiếm 32,4\%.

\subsection{Tỷ lệ sống thêm}

\subsubsection{Thời gian sống thêm}



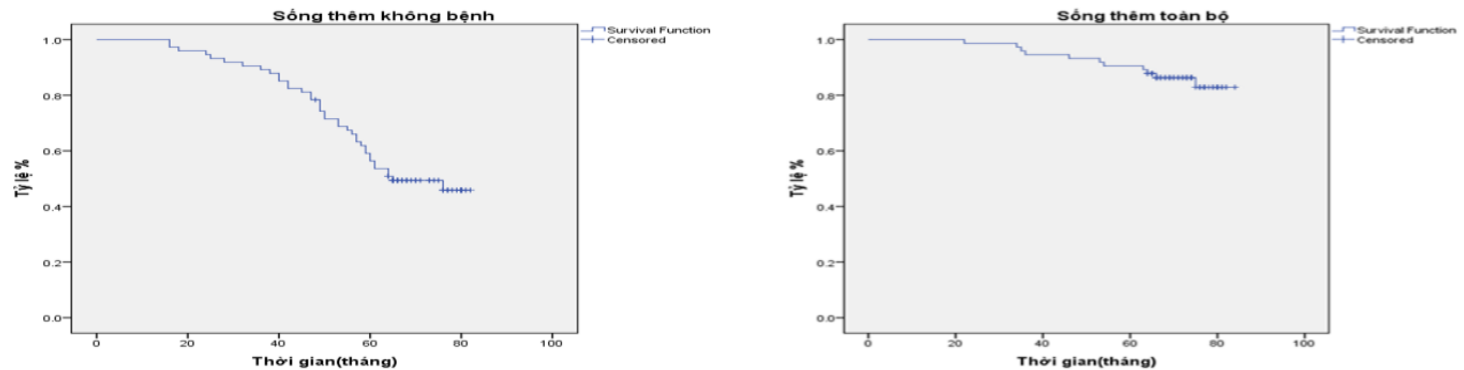

Biểu đồ 1: Tỷ lệ sống thêm không bệnh và sông thêm toàn bộ

Nhận xét: Tỷ lệ DFS $>5$ năm là $53,6 \%$; thời gian sống thêm không bệnh trung bình là $63,95 \pm$ 2,34 tháng. Tỷ lệ OS>5 năm là $89,2 \%$; thời gian sống thêm toàn bộ trung bình là $78,70 \pm 1,60$ tháng.

\subsubsection{Một số yếu tố liên quan đến sông thêm}
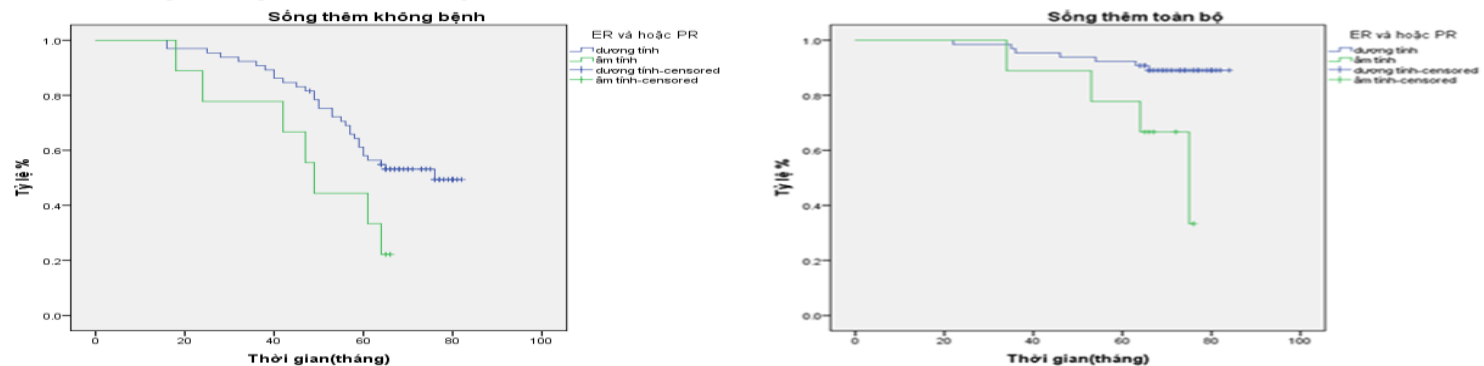

Biểu đồ 3: Sống thêm không bệnh theo tình trạng thụ thể nội tiêt

Nhận xét: Tỷ lệ DFS >5 năm của nhóm có TTNT dương tính chiếm tỷ lệ $58 \%$; còn nhóm có thụ thể nội tiết dương tính là 90,8\%; giảm xuống còn $66,7 \%$ ở nhóm có thụ thể nội tiết âm tính, với $\mathrm{p}<0.05$.
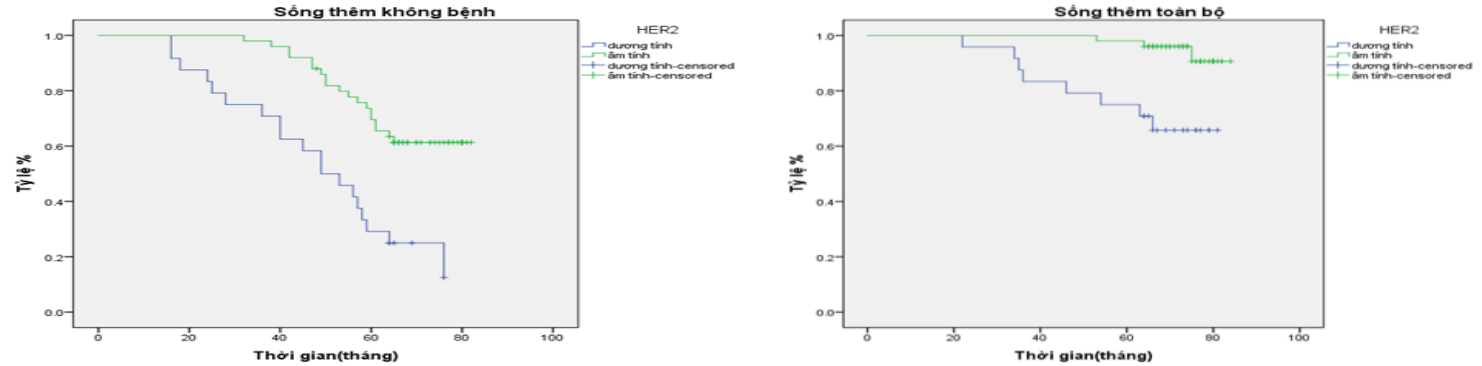

\section{Biểu đồ 4: Sống thêm không bênh theo tình trang thu Her2}

Nhận xét: Tỷ lệ DFS > 5 năm của nhóm Her2(-) là $65,5 \%$; nhóm HER2(+) là $25 \%(p<0,05)$. Tỷ lệ OS > 5 năm của nhóm HER2(-) là $96 \%$; còn nhóm HER2 $(+)$ là $70,8 \%(p<0,05)$.

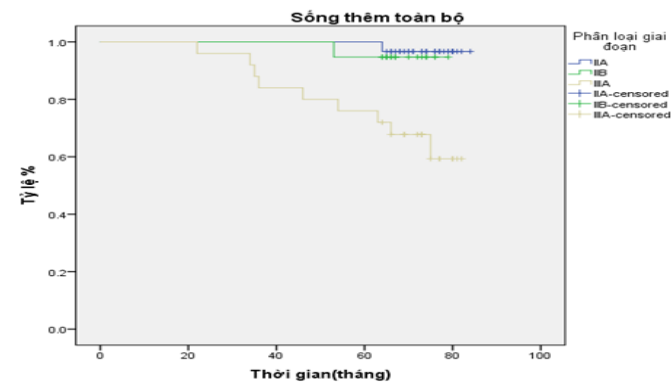

Biểu đồ 2: Sông thêm không bệnh theo giai đoạn bệnh

Nhận xét: Tỷ lệ DFS $>5$ năm giai đoạn IIA, IIB, IIIA cólần lượt là 70\%; 42,1\%; 34,3\% $(p<0,05)$. Tỷ lệ OS> 5 năm giai đoạn IIA, IIB, IIIA lân lượt là 96,7\%; 94,7\%; 72\% ( $p<0,05)$.

\section{BÀN LUẬN}

4.1. Đặc điểm bệnh nhân. Trong nghiên cứu của chúng tôi bệnh nhân cao tuổi nhất là 60 tuổi, trẻ tuổi nhất là 31 tuổi. Đây là độ tuổi phù hợp với một số nghiên cứu của các tác giả trong nước như Lê Thị Sương, Trần Văn Thuấn ${ }^{5,6}$.

Giai đoạn bệnh: là một yếu tố quan trọng liên quan đển tiên lượng cũng như điều trị trong 
UTV. Giai đoạn bệnh càng cao thì tiên lượng càng xâu, sau điều trị thường có nguy cơ tái phát cao. Theo nghiên cứu của Lê Thị Sương cho tỷ lệ giai đoạn IIA, IIB, IIIA lần lượt là $43,8 \%$; $25 \% ; 31,3 \%{ }^{6}$. Kết quả này cũng tương tự nghiên cứu của chúng tôi chủ yếu là giai đoạn IIA với tỷ lệ $40,5 \%$; sau đến giai đoạn IIIA chiếm tỷ lệ $33,8 \%$; cuối cùng là giai đoạn IIB là 25,7\%.

Tình trạng thụ thể nội tiết: thụ thể nội tiết Esstrogen và/ hoặc Progesteron dương tính đáp ứng tốt hơn với điều trị nội tiết, đồng thời tỷ lệ tái phát, di căn thấp hơn và có thời gian sống thêm lâu hơn so với nhóm có TTNT âm tính. Tỷ lệ bệnh nhân có thụ thể nội tiết dương tính (ER và hoặc $P R$ ) là $87,8 \%$; âm tính chỉ chiếm $12,2 \%$. Theo nghiên cứu của Tạ Văn Tờ tỷ lệ thụ thể nội tiết dương tính là 63,3\%; âm tính là 36,6\%7 .

Tình trạng HER2: Bệnh nhân có tý lệ HER2 dương tính là $32,4 \%$; còn dương tính là $67,6 \%$. Cũng tương tự kết quả của T. V. Tờ khi nghiên cứu trên 2207 bệnh nhân cho tỷ lệ Her2 dương tính là $35,1 \%$.

\subsection{Kêt quả điêu trị}

4.2.1. Thời gian sống thêm. Tỷ lệ sống thêm không bệnh sau 5 năm là $53,6 \%$ với thời gian sống thêm không bệnh trung bình là 63,95 $\pm 2,34$ tháng. Tỷ lệ sống thêm toàn bộ sau 5 năm là $89,2 \%$ với thời gian sống thêm toàn bộ trung bình là $78,70 \pm 1,60$ tháng. Kết quả của chúng tôi cao hơn kết quả của Lê Thị Sương khi nghiên cứu trên 32 bệnh nhân cho tỷ lệ sống thêm không bệnh 1 năm, 2 năm, 3 năm lần lượt là $100 \%$; $91,4 \% ; 86,9 \%{ }^{6}$; tỷ lệ sống thêm toàn bộ 1 năm, 2 năm, 3 năm lần lượt là $100 \%$; 95,5\%; 95,5\%; có lẽ do cõ mẫu của chúng tôi lớn hơn. Theo Lý Thị Thu Hiên nghiên cứu trên 103 bệnh nhân UTV có bộ ba âm tính điêu trị bổ trợ 4AC - 4D cho thời gian sống thêm không bểnh 1 năm, 2 năm, 3 năm, 4 năm, 5 năm lần lượt là $95,1 \% ; 93,2 \% ; 92,2 \% ; 89,9 \% ; 89,9 \%$ và thời gian sống thêm toàn bộ 1 năm, 2 năm, 3 năm, 4 năm lần lượt là $100 \% ; 95,1 \%$; 94\%; $90,3 \% ; 90,3 \% 8$.

\subsubsection{Một số yếu tố liên quan đến thời gian sống thêm}

Giai đoạn bệnh: Theo nghiên cứu của chúng tôi giai đoạn bệnh có mối liên quan đến sống thêmtheo tỳ lệ nghịch $(p<0,05)$,giai đoạn càng cao thì thời gian sống thêm càng giảm. Cụ thể trên với các giai đoan IIA, IIB, IIIA cho DFS sau 5 năm lần lượt là $70 \% ; 42,1 \% ; 34,3 \%$; còn tỷ lệ OS sau 5 năm lần lượt là $96,7 \% ; 94,7 \% ; 72 \%$. Nghiên cứu của Trần Văn Thuấn cũng cho tỷ lệ sống thêm không bệnh và sống thêm toàn bộ 4 năm ở giai đoạn II là $92,3 \%$ và $96,1 \%$ giảm xuống còn $65,8 \%$ và $78,2 \%$ ở giai đoạn III $^{5}$.

Thu thể nội tiết: Thu thể nội tiết ầm tính liên quan đến tiên lượng xấu hơn nhóm thụ thể nội tiết dương tính. Trong nghiên cứu của chúng tối tỷ lệ DFS $>5$ năm của nhóm có thụ thể nội tiết dương tính chiếm tỷ lệ gần $58 \%$; còn nhóm có thụ thể nội tiết âm tính chỉ chiếm 33,3\%. Tỷ lệ OS >5 năm của nhóm có thụ thể nội tiết dương tính là $90,8 \%$; giảm xuống còn $66,7 \%$ ở nhóm có thụ thể nội tiết âm tính. Nghiên cứu của Đỗ Thị Kim Anh cũng cho thấy có sự khác biêt về thời gian sống thêm không bệnh và sống thêm toàn bộ ở nhóm có TTNT dương tính và nhóm TTNT âm tính ${ }^{9}$.

Tình trạng Her2: Sự biểu hiện quá mức thụ thể phát triển biểu mô là một yếu tố tiên lượng không tốt, đặc biệt trong trường hợp không được điều trị trúng đích Her2. Theo Trần Văn Thuấn khi phẩn tích đơn biến về ảnh hưởng của Her2 đến kết quả sống thêm sau 4 năm thì tỷ lệ sống thêm không bệnh và sông thêm toàn bộ ở nhóm Her2 âm tính là $82,1 \%$ và $98,51 \%$ cao hơn so với $57,81 \%$ và $77,37 \%$ ở nhóm Her2 dương tính, với $p<0,05^{5}$. Tương tự kết qủa của chúng tôi tỷ lệ DFS sau 5 năm của nhóm Her2(-) là 65,5\%; giảm xuống $25 \%$ ở nhóm Her2(+). Tỷ lệ OS sau 5 năm ở hai nhóm trên lần lượt là $96 \%$ và $70,8 \%$. Sự khác biệt này có ý nghĩa thống kê với $p<0,05$.

\section{KẾT LUÂ̂N}

Bệnh nhân nghiên cứu có độ tuổi trung bình 46,6 tuổi. Giai đoạn IIA có tỷ lệ 40,5\%; tiếp đến giai đoan IIIA chiếm tỷ lê $33,8 \%$; và giai đoan IIB là 25,7\%. Tỷ lệ TTNT dương tính cao 87,8\%; tình trạng HER2 âm tính có tỷ lệ 76,6\%.

74 bệnh nhân UTV giai đoạn II-IIIA được điều trị hóa chất bổ trợ phác đồ $4 A C-4 D$, thời gian sống thêm không bệnh sau 5 năm trung bình là $63,95 \pm 2,34$ tháng và thời gian sống thêm toàn bộ sau 5 năm là $78,70 \pm 1,60$ tháng. Giai đoạn bệnh, tình trạng TTNT và HER2 là những yếu tố tiên lượng quan trong có liên quan đến kết quả sống thêm trong nhóm nghiên cứu.

Phác đồ $4 A C-4 D$ là phác đồ có hiệu quả cao cho bệnh nhân ung thư vú giai đoạn II-IIIA bổ trợ tại bệnh viện Ung bướu Thanh Hóa.

\section{TÀI LIỆU THAM KHẢO}

1. Paridaens R., Biganzoli L., Bruning P., et al. (2000). Paclitaxel versus doxorubicin as first-line single-agent chemotherapy for metastatic breast cancer: a European Organization for Research and Treatment of Cancer Randomized Study with cross-over. J Clin Oncol, 18(4), 724-733. 
2. Falkson G, Gelman RS, Tormey DC, Cummings FJ, Carbone PP, Falkson HC. The Eastern Cooperative Oncology Group experience with cyclophosphamide, adriamycin, and 5fluorouracil (CAF) in patients with metastatic breast cancer. Cancer. 1985;56(2):219-224. doi:10.1002/1097-0142(19850715)56:2<219::aidcncr2820560202>3.0.co;2-q

3. Tranum BL, McDonald B, Thigpen $T$, et al. Adriamycin combinations in advanced breast cancer. A Southwest Oncology Group Study. Cancer. 1982;49(5):835-839. doi:10.1002/10970142(19820301)49:5<835: :aidcncr2820490502>3.0.c0;2-z

4. Taylor SG, Gelber RD. Experience of the Eastern Cooperative Oncology Group with doxorubicin as a single agent in patients with previously untreated breast cancer. Cancer Treat Rep. 1982; 66(7): 1594-1595.
5. Trân Văn Thuấn. Đánh giá kết quả điều trị bổ trơ hóa chất phác đồ Adriamycin-Cyclophosphamid kết hợp với điêu trị nội tiết trên bệnh nhân ung thư vú giai đoạn II-III. Luânn văn tiến sỹ; 2005.

6. Lê Thị Sương. Đánh giá kết quả điều trị bổ trơ ung thư vú giai đoạn II-IIIA bằng phác đồ 4AC-4D Luấn văn thac sỹ; 2017.

7. Ta Văn Tờ. Nghiên cứu hình thái hoc, hóa mô miễn dịch và giá trị tiên lượng của chúng trong ung thư biểu mô tuyến vú. Luận văn Tiển sỹ Y hoc; 2004.

8. Lỳ Thi Thu Hiên. Đánh giá hiệu quả điều tri bổ trợ phác đồ 4AC- 4D trên bệnh nhân ung thư vú có bố ba âm , Luận văn thạc sỹ்; 2018.

9. Đố Thi Kím Ành. Đánh giá kết quả hóa chất bổ trơ phác đồ 4AC-4P trên bệnh nhân ung thư vú gia đoạn II-III tại bệnh viện K luận văn thạc sỹ; 2008.

\section{TÌM HIỂU VAI TRÒ CỦA TỶ LÊ SV2/RV3 TRÊN ĐIÊN TÂM ĐỒ TRONG CHẨN ĐOÁN PHÂN BIÊT NGOAI TÂM THU THẤT Có NGUÔNN GỐC ĐƯờNG RA THẤT PHẢI VÀ ĐƯỜNG RA THẤT TRÁI}

\section{TÓM TẮT}

Các rối loạn nhip thất trên người không có bênh tim thực tổn, hay còn được gọi là các rối loạn nhịp thất vồ căn (idiopathic ventricular arrhythmias), đa phần đều khởi phát từ đường ra tâm thất. Phân biệt ngoai tâm thu thất từ đường ra thất phải và đường ra thất trái chẩn đoán còn khó khăn, đặc biệt là rối loạn nhịp thất có dạng block nhánh trái với chuyển tiếp tại V3. Mục tiêu của nghiên cứu chúng tôi là: mô tả các đặc điểm điện tâm đồ bề mă̆t của ngoại tâm thu thất có nguồn gốc từ đường ra thất phải và đường ra thất trái; đồng thời tìm hiểu vai trò của tỷ lệ SV2/RV3 trên điện tâm đồ bề mặt trong chẩn đoán phân biệt ngoại tâm thu thất có nguồn gốc ở đường ra thất trái và đường ra thất phải. Đối tượng và phương pháp nghiến cứu: mô tả cắt ngang 150 bệnh nhân ngoại tâm thu thất không có bênh tim thực tổn và có chì định thăm dò điện sinh lý và điều trị RF. Kết quả nghiên cứu: chúng tôi tiến hành nghiên cứu 150 bệnh nhân có ngoại tâm thu thất dạng block nhánh trái đã được thăm dò điên sinh lý và triệt đốt RF thành công ở đường ra thất phải (ĐRTP; $n=110$ ) hoăc đường ra thất trái (ĐRTT; $n=40$ ). Các kích thước biển độ sóng được đo đạc bằng thước cặp điện tử. Tỷ lệ SVं2/RV3 chính là biên độ sóng $S$ ở chuyển đao V2 chia cho biên độ sóng $R$ ở chuyển đạo V3 của nhịp ngoại tâm thu thất. Kết quả chỉ số SV2/RV3 ở đường

*Bênh viện Thanh Nhàn Hà Nội,

**Viên Tim mach Viêt Nam-Bênh viên Bach Mai

Chịu trách nhiệm chính: Nguyễn Thị Lan Anh

Email: lananhnguyenthi0502@gmail.com

Ngày nhận bài: 10.8.2021

Ngày phản biên khoa hoc: 4.10 .2021

Ngày duyệt bài: 15.10 .2021

\section{Nguyễn Thị Lan Anh*, Phạm Trần Linh**}

ra thất trái nhỏ hơn đáng kể so với đường ra thất phải có ý nghĩa thống kê $(1,23 \pm 0,78$ so với $6,07 \pm 6,32$ và $p<0,001)$. Diện tích duới đường cong (AUC) cho chỉ số SV2/RV3 là 0,934 , với giá trị tới hạn là $\leq 1,6$ dứ đoán ngoại tâm thu thất đường ra thất trái với độ nhạy $90,9 \%$ và độ đặc hiệu là $80 \%$. Khi so sánh chỉ số này với 1 số các chỉ số khác ở cả nhóm bệnh nhân nghiên cứu và nhóm bệnh nhân có chuyển tiếp tại V3 chúng tôi nhận thấy chỉ số của chúng tôi cho kết quả cao nhất về giá trị dưới đường cong ROC và độ nhạy, độ đặc hiệu. Chỉ số này còn rất có giá trị ứng dụng lâm sàng cho các nhà nhịp hoc do tính toán khá dể dàng và nhanh chóng chỉ với điện tâm đồ thường quy 12 chuyển đạo. Kết luận: Chỉ số tỷ lệ SV2/RV3 rất có giá trị trong chẩn đoán phân biệt ngoại tâm thu thất đường ra thất trái và đường ra thất phải, hữu dụng trên thực hành lâm sàng cho các bác sỹ nhịp học.

Tư khóa: Ngoại tâm thu thất, Ngoại tầm thu thất đường ra thất, Điện sinh lý.

\section{SUMMARY}

\section{ROLE OF ELECTROCARDIOGRAPHIC SV2/RV3 RATIO IN DIFERENTIAL DIAGNISIS OF VENTRICULAR} EXTRASYSTOLE ORIGINATING FROM RIGHT VENTRICULAR OUTFLOW TRACT AND LEFT VENTRICULAR OUTFLOW TRACT

Introduction: Ventricular arrhythmias in humans without structural heart disease, also known as idiopathic ventricular arrhythmias, mostly originate in the ventricular outflow tract. Distinguishing ventricular extrasystoles from right ventricular outflow tract or left ventricular outflow tract remains challenging, especially in the form of ventricular arrhythmias with left bundle branch block with transition at V3. The 